\title{
Religious Service Attendance and Allostatic Load Among High-Functioning Elderly
}

\section{Citation}

Maselko, Joanna, Laura Kubzansky, Ichiro Kawachi, Teresa Seeman, and Lisa Berkman. 2007. "Religious Service Attendance and Allostatic Load Among High-Functioning Elderly." Psychosomatic Medicine 69 (5): 464-72. https://doi.org/10.1097/psy.0b013e31806c7c57.

\section{Permanent link}

http://nrs.harvard.edu/urn-3:HUL.InstRepos:41288262

\section{Terms of Use}

This article was downloaded from Harvard University's DASH repository, WARNING: This file should NOT have been available for downloading from Harvard University's DASH repository.

\section{Share Your Story}

The Harvard community has made this article openly available.

Please share how this access benefits you. Submit a story.

\section{Accessibility}




\title{
Religious Service Attendance and Allostatic Load Among High-Functioning Elderly
}

\author{
Joanna Maselko, ScD, Laura Kubzansky, PhD, Ichiro Kawachi, MD, PhD, Teresa Seeman, PhD, and Lisa Berkman, PhD
}

\begin{abstract}
Objective: To examine the association between frequency of religious service attendance and an index of cumulative physiological dysregulation as measured by allostatic load (AL) (systolic and diastolic blood pressure, waist/hip ratio, high-density lipoprotein and total cholesterol, glycosylated hemoglobin, cortisol, serum dihydroepiandrosterone sulfate, norepinephrine, and epinephrine).There is growing empirical evidence of a positive relationship between religious engagement and better clinical health outcomes. However, studies exploring the subclinical levels of physiological dysregulation are rare; hence, the physiological processes underpinning the religion-health relationship are not well understood. Methods: In 1988, 853 participants from the MacArthur Successful Aging Study provided information on the frequency of religious service attendance as well as blood and urine samples needed to obtain measures for a ten-item cumulative AL index. Gender-stratified multivariate linear regression models were used to estimate the direction and magnitude of the association between weekly religious service attendance and AL. Results: At least weekly religious service attendance was associated with lower AL levels among women $(b=-0.47 ; p<.01)$, but not among men $(b=0.02 ; p=.88)$ in models that statistically controlled for age, income, education, marital status, and level of physical functioning. This relationship could not be attributed to the association between religious attendance and any one or two of the components of the AL index. It also was not explained by either higher physical functioning or social integration. Conclusion: Cumulative physiological dysregulation may be one mechanism through which religious engagement may influence a diverse range of clinically relevant health outcomes. Key words: religious activity, allostatic load, physiological dysregulation, aging, gender, social networks.
\end{abstract}

IL-6 = interleukin-6; HPA = hypothalamic-pituitary-adrenal; EPESE = epidemiologic studies of the elderly; HDL $=$ high-density lipoprotein; DHEA-S = dihydroepiandrosterone sulfate; $\mathbf{O R}=$ odds ratio; $\mathbf{C I}=$ confidence interval; $\mathbf{C H D}=$ coronary heart disease; $\mathbf{A L}=$ allostatic load; $\mathbf{S E S}=$ socioeconomic status.

\section{INTRODUCTION}

$\mathrm{T}$ here is growing evidence that religious engagement is associated with better physical and psychological health $(1,2)$. For example, attendance at religious services is associated with reduced risk of death from a wide range of causes $(3,4)$. There is also evidence that religious activity is protective against the development of specific diseases such as cardiovascular disease (5) and that it is associated with less disability when a disease is present $(1,6)$. Improved theoretical and methodological approaches have produced a growing number of high-quality studies; consequently, the association between religious engagement and health has gained wider acceptance (7-9). However, the pathways and mechanisms through which religious engagement may affect health are far from understood, and the physiological processes underlying the religion-health connection remain largely unknown (10).

To address this issue, researchers have begun to examine preclinical biomarkers associated with religious engagement as a way to understand how it may influence biological changes that ultimately affect disease processes (10-14). Studies that address this question focus on individual param-

From the Department of Public Health (J.M.), Temple University, Philadelphia, Pennsylvania; Department of Society, Human Development and Health (L.K., I.K., L.B.), Harvard School of Public Health, Cambridge, Massachusetts; and Department of Epidemiology (T.S.), University of California, Los Angeles, Los Angeles, California.

Address correspondence and reprint requests to Joanna Maselko, Department of Public Health, Temple University, 1700 N Broad St., Suite 300B, Philadelphia, Pennsylvania. E-mail: maselko@temple.edu

Received for publication September 19, 2005; revision received February $27,2007$.

The study was partially supported by Grant MH17119 from the National Institutes of Health (J.M.).

DOI: $10.1097 /$ PSY.0b013e31806c7c57 eters from a single biological system such as cardiovascular (e.g., blood pressure), metabolic (e.g., cholesterol), hypothalamic-pituitary-adrenal (HPA) axis (e.g., cortisol), or inflammatory (e.g., interleukin-6 (IL-6)) parameters. For example, at least two groups of researchers have reported an association between religious service attendance and lower IL-6 levels $(12,13)$. In one study, evidence showed that lower IL-6 levels mediated the protective relationship between religious service attendance and lower mortality rates (13). In another crosssectional study on blood pressure, Koenig et al. found a small, but statistically significant, inverse association of blood pressure with church attendance and private prayer, although they found no significant effects on change in blood pressure over time (11). A recent review of 35 studies assessed the strength of the evidence for biological pathways in the religion-health relationship. The authors found that the highest-quality evidence to date was for a connection between religiosity/spirituality (measured a number of different ways) and blood pressure as well as blood pressure reactivity to stress. The review concluded that, although much more research is needed, the results do support the hypothesis that religious engagement may have direct physiological effects that promote health and well-being (10). One limitation of the studies reviewed was that each examined only one or two physiological parameters and thus provided only limited understanding of the overall, systemic, physiological differences between those who are and are not religiously active. Moreover, because the vast majority of higher-quality studies focused specifically on blood pressure, it was unclear if other biological pathways are not involved or if they have not been researched adequately enough.

\section{Allostasis Framework}

Associations between religious engagement and individual biological markers, such as those stated above, provide a single snapshot of functioning in one specific physiological system. A more comprehensive index that is representative of 
one's overall physiological state may yield even more meaningful information (10). Allostatic load (AL) is a concept introduced by McEwen and Stellar intended to measure overall physiological wear and tear on one's body, which serves as a preclinical marker of pathophysiologic processes that precede the onset of disease (15). The basic premise is that adaptation to the demands of everyday living requires the body to react physiologically to a wide variety of stressors, a dynamic process referred to as allostasis. With repeated or unrelenting demands over time, this process may become damaging if, for example, a physiological system is not able to habituate to a stimuli; if it remains in an activated state after the stimuli has passed; or if the response is not sufficiently adequate to counter the effect of the stimuli (16). The body's ability to react successfully to external stressors and to maintain system parameters within normal operating ranges is then reduced, making it more vulnerable to disease (17). AL is thus conceptualized as a measure of the total accumulation of dysregulation across multiple physiological systems and is posited to mediate the effects of stress and related psychosocial exposures on health risks (18). Measures of AL have incorporated multiple regulatory systems by including parameters that index functioning in the HPA axis, the cardiovascular, immune, and sympathetic nervous systems, as well as metabolic processes. Empirical evidence supports the hypothesis that higher AL is associated with poorer health. It has prospectively predicted clinically relevant outcomes including incident cardiovascular events, physical function, cognitive decline, and mortality (19-21). These findings provide evidence that AL captures physiological changes that precede the occurrence of clinical disease and, hence, represents a meaningful step in the disease development process. As a result, consideration of the relationship between an exposure of interest and $\mathrm{AL}$ may give some insight into the mechanisms (i.e., physiological processes) by which the exposure may ultimately influence specific health outcomes.

\section{Disentangling Relationships}

Emerging evidence that social relationships and other social determinants may influence $\operatorname{AL}(22,23)$ has led to a better understanding of the biological pathways involved in the "embodiment" of social experiences. For example, one recent study found that positive social experiences such as affirming parental and spousal relationships predicted lower levels of AL (23). Other work has found that the simple presence of close friends or neighbors, regardless of the subjective quality of these relationships, is associated with lower AL among elderly men and women (24). The fact that these same social experiences are linked with a wide range of disease outcomes, together with growing evidence that $\mathrm{AL}$ predicts onset of disease, suggests that $\mathrm{AL}$, or cumulative dysregulation, may be an important mechanism connecting a wide range of social exposures to health.

Based on these findings, we hypothesize that AL is a mechanism by which religious engagement, with its substantial social component of belonging to a religious community and attending religious services, may influence disease outcomes (Figure 1). A connection between religious engagement and $\mathrm{AL}$ would therefore shed light on the potential physiological mechanisms underpinning the empirical evidence that religious engagement is associated with a wide range of diseases.

One notable challenge for this research is to disentangle the effects of religious activity from the more general effects of social relationships on health. Several researchers have suggested that the positive association between religious activity and better health can be explained by the increased social networks and social support available to persons who belong to a religious community $(25,26)$. Others have argued that involvement with a religious community is actually a marker of a more complex phenomenon assumed to include other behaviors, beliefs, or experiences potentially relevant to health (27). Although religiosity includes both a social and a private component, measures of attendance frequency invariably capture a more social dimension. This distinction becomes especially relevant when hypothesizing the pathways through which religious engagement may influence health. For example, attending public religious activities is an opportunity for the creation and maintenance of both weak and strong ties. Churches or synagogues often organize dinner socials, bingo nights, or other activities that encourage friendship among members (28). A simple increase in the size of one's social network can have health-promoting consequences, especially given that social isolation is a significant risk factor for negative health outcomes among the elderly (29). Previous research has also shown that persons who participate in public religious activities tend to be more socially integrated in other parts of their lives (30). Thus, an important task for research on religious attendance is to distinguish between health effects due to enhanced social integration and those due to behaviors or beliefs more uniquely associated with religious activity.

\section{Study Goals}

The primary goal of this study is to examine the relationship between religious service attendance and physiological

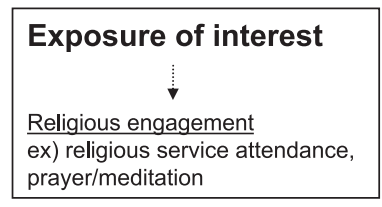

A
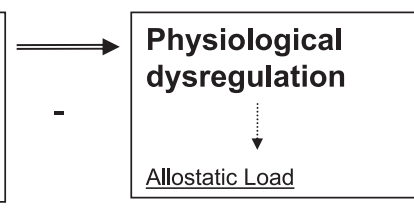

B

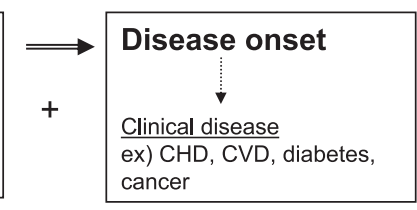

C


coronary heart disease; CVD = cardiovascular disease. 
"wear and tear" as measured through AL (linking A to B in Figure 1). A secondary goal is to look for evidence that any observed association may be mediated by increased social networks/supports among those who are religiously active. To our knowledge, this is the first study that investigates the association between religious service attendance and AL. Our study is based on a high- functioning elderly cohort, allowing for a more systematic examination of the potential mechanisms in the relationship between religious activity and disease outcomes before the onset of disability and other health problems often found in elderly samples.

\section{METHODS}

\section{Sample}

The data come from the 1988 wave of the MacArthur Successful Aging Study. The sample is comprised of adults aged 70 to 80 years, who were subsampled from the Established Population for Epidemiologic Studies of the Elderly (EPESE) cohort based on their age eligibility and functional status (31). Subjects were selected from three communities that comprise the three sites of EPESE-Durham, NC; East Boston, MA; and New Haven, CT. Respective institutional review panels approved the study and consert procedures at each study site. Age range was restricted to minimize the effects of age in subsequent analyses. To identify a cohort of approximately the top third of individuals in terms of high-functional ability, the sample was screened according to the following six criteria related to physical and cognitive function: 1) no disability on a 7-item Activities of Daily Living Scale (32); 2) presence of at most one physical function disability, such as being able to climb stairs or move heavy objects $(33,34) ; 3)$ ability to sustain a 10 -second semitandem balance; 4 ) ability to stand up successfully from a seated position five times in a 20-second period; 5) a score of at least 6 out of 9 on the Short Portable Mental Status Questionnaire (35); and 6) recall of at least three of six elements from a short story. Participants had to score well in both the physical and cognitive domains to be eligible for the study. Using the above criteria, we invited 1313 individuals to participate and 1189 (90.6\%) persons gave their consent. Participants who enrolled in the MacArthur study were more likely to be white and more highly educated as compared with their middleand low-functioning counterparts. They were also more involved in their communities and reported higher levels of psychological well-being (31). Ultimately, 853 (72\%) participants had complete and valid data for both AL and religious service attendance. The remaining $28 \%$ of participants who did not have complete data did not differ in age, educational attainment, or gender from those who had complete data. However, participants with complete scores did report slightly higher incomes than those with incomplete scores.

\section{Religious Activity}

Religious activity was assessed through a question about the frequency of attending religious services. Response options included 1) more than once a week, 2) once a week, 3) two to three times a month, 4) once a month, 5) less than once a month, and 6) never. We dichotomized this variable and defined a weekly attendee as a person who attended religious services at least once a week and a less than weekly attendee as someone who attended two to three times a month or less.

For the subset of the sample residing in New Haven, CT $(n=232)$, additional data were available from the 1982, 1985, and 1988 EPESE interview on subjective religiosity, denominational affiliation, and number of persons known in one's congregation. Subjective religiosity was assessed by asking, "Aside from attendance at religious services, do you consider yourself to be: deeply religious, fairly religious, only slightly religious, not at all religious, or against religion?" In 1982 and 1988, roughly 70\% of those who said they were fairly or deeply religious also reported attending services regularly. Denominational options included Catholic, Protestant, Jewish, Other, and None. Participants (whether they currently attended services or not) were also asked how many people in their congregations they knew personally. The response categories included none, a few (1-5), many, or almost all. As noted in the data analysis section, this subset dataset was used for additional analyses on subjective religiosity and social networks.

\section{Allostatic Load}

Biological markers capturing dysregulation in the cardiovascular system, metabolic process, sympathetic nervous system, and HPA axis were available for the creation of the AL index. According to previous work (21), ten biomarkers (itemized below) were used to derive the final AL score: systolic and diastolic blood pressure reflected cardiovascular activity; waist/hip ratio served as an indicator of metabolism and adipose tissue deposition; highdensity lipoprotein (HDL) and total cholesterol reflected cardiovascular health; glycosylated hemoglobin reflected glucose metabolism; cortisol excretion reflected HPA axis activity; serum dihydroepiandrosterone sulfate (DHEA-S) also reflected HPA axis activity but as an antagonist to cortisol's effects; and norepinephrine and epinephrine were markers of sympathetic nervous system activity.

Specifically, for systolic (1) and diastolic (2) blood pressure, three seated readings were taken and the final score was based on the mean of the second and third readings. For the waist/hip ratio (3), the waist measurement was calculated using the circumference at the narrowest point between the ribs and the iliac crest and the hip measurement was taken at the largest point around the buttocks. Blood samples were collected and used to assess HDL (4) and total cholesterol (5), glycosylated hemoglobin (6), and DHEA-S (7). These measures have been described previously (31). An overnight 12-hour urine sample was collected to measure cortisol (8), norepinephrine (9), and epinephrine (10). Participants were asked to complete an overnight urine collection from 8:00 PM on the evening after their home interview to 8:00 AM the next morning. The values for cortisol, epinephrine, and norepinephrine were adjusted for body size and renal function using the 12-hour creatinine excretion rate. Using these parameters, a cumulative index of AL was created. If the value for any of the ten components fell within the high-risk quartile of the distribution for that component, 1 point was assigned for that component (Table 1). Scores for all components were summed to create the AL score. Every individual thus has an AL value, which ranges from 0 to 10 with higher scores reflecting greater system dysregulation. AL scores ranged from 0 to 8 , with almost a quarter of the sample scoring 0 or 1 . An AL score of $\geq 5$ was considered high, according to the characterization of Seeman et al. (23). The validity of this measure has been examined in a number of studies. Previous research has examined the advantages of the ten-item AL score over the components that make up Syndrome X, which focuses on cardiovascular risk factors (21). The components that were unique to the AL measure were better able to predict mortality and physical functioning, whereas the Syndrome $X$ components were strongly associated with cardiovascular outcomes and cognitive decline (21). Furthermore, studies using different forms of the AL score itself have found them to perform equivalently $(20,21,36,37)$.

TABLE 1. Allostatic Load Components and Cut-Offs

$\begin{array}{ll}\text { Highest quartile } & \\ \text { SBP } & \geq 148 \mathrm{~mm} \mathrm{Hg} \\ \text { DBP } & \geq 83 \mathrm{~mm} \mathrm{Hg} \\ \text { WHR } & \geq 0.94 \\ \text { Ratio total cholesterol/HDL } & \geq 5.9 \\ \text { Glycosylated hemoglobin } & \geq 7.1 \% \\ \text { Urinary CL } & \geq 25.7 \mu \mathrm{g} / \mathrm{g} \text { creatinine } \\ \text { Urinary NE } & \geq 48 \mu \mathrm{g} / \mathrm{g} \text { creatinine } \\ \text { Urinary EPIN } & \geq 5 \mu \mathrm{g} / \mathrm{g} \text { creatinine } \\ \text { Lowest quartile } & \leq 37 \mathrm{mg} / \mathrm{dl} \\ \text { HDL cholesterol } & \leq 350 \mathrm{ng} / \mathrm{ml} \\ \text { DHEA-S } & \end{array}$

$\mathrm{SBP}=$ systolic blood pressure; $\mathrm{DBP}=$ diastolic blood pressure; WHR $=$ waist/hip ratio; $\mathrm{HDL}=$ high-density lipoprotein; $\mathrm{CL}=$ cortisol; $\mathrm{NE}=$ norepinephrine; EPIN = epinephrine; DHEA-S = dihydroepiandrosterone sulfate. 


\section{RELIGIOUS ACTIVITY AND PHYSIOLOGICAL DYSREGULATION}

\section{Social Networks and Supports}

The measures of social networks and social supports were drawn from various sources (38-41) and the present analysis focuses on the presence of particular types of social ties and the extent to which these ties provide emotional and instrumental support. The measure of social ties is a count of the number of friends and relatives (including children) who live nearby and the frequency with which the respondent makes visual contacts with members of this network. Social support focused on the quality of emotional and instrumental support (42). The measure of emotional support was based on the average reported frequency with which members of the respondent's social network made the respondent "feel loved" and "listened to when they had a problem." The measure of instrumental support was based on the average reported frequency with which network members "helped with daily tasks" and "provided information."

\section{Covariates}

Other variables used in the analyses included age, gender, ethnicity (self-identified white versus non-white), income (in $\$ 5000$ increments and poor/nonpoor using $\$ 10,000$ cut-off), education in years, marital status (currently married versus not), physical functioning, and presence of coronary heart disease (CHD), diabetes, or cancer. The physical functioning scale is a sum of five domains assessing lower- and upper-body strength, balance, and dexterity assessed via performance tests. Performance tasks included walking, tapping feet alternating between circles 1-foot apart while seated, sitting down and getting up from a chair, keeping balance standing with eyes open and closed, and signing one's name. The final score was calculated according to the participant's ability and speed with which they completed the task (43). Physical functioning was used to control for baseline disability, which might be associated with both lower religious service attendance and higher AL.

\section{Data Analysis}

Ordinary least-squares multivariate linear regression was the primary method used to assess the cross-sectional association between religious service attendance and $\mathrm{AL}$. We performed $t$ tests to compare $\mathrm{AL}$ scores across groups (e.g., men/women), $\chi^{2}$ tests to compare categorical variables, and logistic regression for modeling individual AL components and the high AL score. All analyses were conducted using SAS, version 9. The independent variable is defined as weekly religious service attendance (yes/no). The main dependent variable is the $\mathrm{AL}$ score treated as a continuous variable. Given previous research suggesting the association between religious activity and health may differ for men and women $(4,44)$, all models were stratified by gender and a formal test of a gender by attendance interaction was performed. Models were presented as full multivariate models controlling for age, income, education, race, marital status, and physical functioning.

\section{RESULTS}

The mean age of the sample $(n=853)$ was 74.2 years, with $54 \%$ of the sample comprised of women and $82 \%$ were white participants (Table 2). Women reported higher levels of religious engagement than men; $65 \%$ of women reported attending religious services weekly compared with $50 \%$ of men $\left(\chi^{2}(1,853)=19.4 ; p<.001\right)$. Service attendance was not related to educational attainment, and a higher proportion of those who were non-white attended services weekly as compared with those who were white.

The supplemental data from the New Haven EPESE participants $(n=232)$ suggested that the religious attendance variable was reliable and stable. For example, $90 \%$ of persons who reported at least weekly service attendance in the 1988 MacArthur survey also reported at least weekly attendance during the 1988 EPESE interview. Additionally, the overall correlation between religious service attendance in 1982 and 1988 was $0.72(p \leq .001)$ and $89 \%$ of those who went weekly or more in 1982 reported the same frequency in 1988. Overall, during this 6-year period, roughly the same number of persons increased their frequency of attendance as decreased it (22\% versus $23 \%$ ), resulting in an overall stable frequency of attendance in the 6 years preceding the data collection for the current study. Subjective religiosity also did not seem to significantly change over time. This finding is consistent with previous research showing that the often-cited higher rate of religious behaviors among the elderly is not due to the elderly's increased religious behaviors but due to their steady religious behavior throughout their lives. Persons born in the first half of the 20th century have reportedly been more religious throughout their lives as compared with their younger counterparts (45).

The overall AL score was $2.66 \pm 1.53$ (mean \pm standard deviation) and there was no significant difference in the scores of women versus men $(2.60$ versus $2.72 ; t(851)=1.14 ; p=$ $.25)$. AL was only weakly associated with age $(r=.09 ; p=$ .01 ), but this is not surprising given the narrow age range of the participants.

TABLE 2. Characteristics of MacArthur Cohort Broken Down by Gender and Weekly Religious Service Attendance

\begin{tabular}{|c|c|c|c|c|}
\hline & \multicolumn{2}{|c|}{ Men } & \multicolumn{2}{|c|}{ Women } \\
\hline & $\begin{array}{l}\text { At Least Weekly } \\
\quad(n=195)\end{array}$ & $\begin{array}{l}\text { Less Than Weekly } \\
\quad(n=198)\end{array}$ & $\begin{array}{l}\text { At Least Weekly } \\
\quad(n=297)\end{array}$ & $\begin{array}{l}\text { Less Than Weekly } \\
\qquad(n=163)\end{array}$ \\
\hline $\begin{array}{l}\text { Age, years, mean } \pm S D \\
\quad(\text { range } 70-80)\end{array}$ & $74.2 \pm 2.8$ & $74.0 \pm 2.7$ & $74.4 \pm 2.7$ & $74.4 \pm 2.7$ \\
\hline $\begin{array}{l}\text { Education, mean } \pm \text { SD } \\
\quad \text { (range } 0-17)\end{array}$ & $10.8 \pm 3.7$ & $10.6 \pm 3.8$ & $10.8 \pm 2.9$ & $10.5 \pm 3.0$ \\
\hline Income, \% earning $<\$ 10,000 /$ year & 24 & 31 & 51 & 61 \\
\hline Married, \% & 72 & 64 & 31 & 35 \\
\hline Non-white, \% & $26^{a}$ & $5^{b}$ & $23^{a}$ & $10^{b}$ \\
\hline Physical function, mean \pm SD (range 0.6-3.8) & $2.9 \pm 0.4$ & $3.0 \pm 0.4$ & $2.7 \pm 0.5$ & $2.6 \pm 0.5$ \\
\hline Allostatic load, mean \pm SD (range $0-8)$ & $2.7 \pm 1.6$ & $2.7 \pm 1.6$ & $2.4 \pm 1.4^{a}$ & $2.9 \pm 1.6^{b}$ \\
\hline
\end{tabular}

\footnotetext{
${ }^{a, b}$ Set of numbers significantly different from each other at $p<.05$.
} 


\section{J. MASELKO et al.}

\section{Religious Service Attendance and Allostatic Load}

Figure 2 shows AL scores by frequency of religious service attendance for men and women. A pattern was apparent among women with AL generally lower among those with higher frequency of service attendance. Among men, the AL score did not differ by the level of service attendance and we did not observe any significant trends.

Table 3 presents results from linear regression models, stratified by gender. Model 1 presents the main multivariate models, which adjust for income, education, ethnicity, marital status, and physical functioning, whereas model 2 also adjusts for a concurrent diagnosis of $\mathrm{CHD}$, diabetes, and cancer. Among women, weekly religious service attendance was inversely associated with $\mathrm{AL}$ in the multivariate model $(b=$ -0.47 ; standard error $(\mathrm{SE})=0.15 ; p=.002$ ). Furthermore, weekly attendance among women was associated with a decreased risk of having a high AL $(\geq 5)$ with an odds ratio (OR) of 0.39 (95\% Confidence Interval (CI): $0.20-0.76$ ). Religious service attendance was not associated with $\mathrm{AL}$ among men, in either model. To formally test whether the gender difference was statistically significant, we ran a model with an interaction term between gender and weekly attendance. This significant term $(b=0.45 ; \mathrm{SE}=0.22 ; p=.04)$ in the multivariate model provided evidence of an interaction. The findings from model 2 explore possible confounding by the presence of chronic conditions ( $\mathrm{CHD}$, diabetes, and cancer) that may be associated with $\mathrm{AL}$ and changes in religious activity, above and beyond the impact of changing physical function. Adding these covariates did not affect the strength of the association between service attendance and AL.

Given that the AL score is meant to capture dysregulation in multiple physiological systems, we explored which systems are affected and to what extent. We examined whether the observed association with religious service attendance was driven by specific components comprising the AL index. This closer examination showed that women who attended services weekly had a lower odds of having high epinephrine levels $(\mathrm{OR}=0.55 ; 95 \% \mathrm{CI}: 0.36-0.83)$ and were also less likely to have a high waist/hip ratio (OR $=0.34 ; 95 \%$ CI: $0.18-0.67)$ (Table 4). However, these two factors were not responsible for the entire association between religious service attendance and AL. Further analyses demonstrated that even after removing high epinephrine and waist/hip ratio from the total AL score,

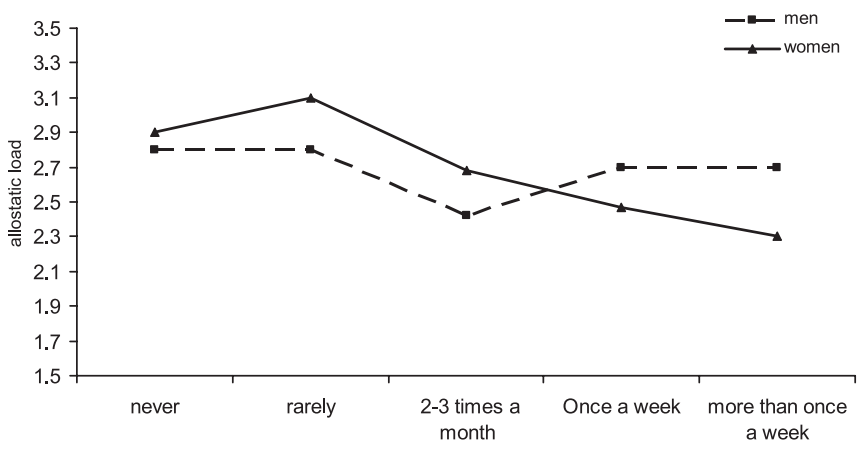

Figure 2. Religious service attendance and allostatic load. a marginally significant association between religious service attendance and $\mathrm{AL}$ remained $(\beta=-0.23$; $\mathrm{SE}=0.13 ; p=$ $.08)$ in the women's multivariate model. Among men, of the ten AL components, weekly service attendance was associated with higher systolic blood pressure $(\mathrm{OR}=1.80 ; 95 \% \mathrm{CI}$ : $1.12-2.90)$ and lower waist/hip ratio $(\mathrm{OR}=0.61 ; 95 \% \mathrm{CI}$ : $0.39-0.93)$. The association with higher blood pressure was surprising; men who attended weekly service had higher blood pressure by $3.5 \mathrm{~mm} \mathrm{Hg}$ when compared with men who attended services less frequently (136.2 versus $139.7 ; t(378)=$ $1.86 ; p=.06$ ). Results from additional models where each of the individual AL components were treated as continuous variables instead of dichotomous were identical, with the exception that weekly attendance was not associated with higher epinephrine among women.

\section{Social Networks and Social Support}

Women who attended services weekly reported having more frequent contacts with larger social networks. For example, weekly attendees had, on average, 7.4 close geographic contacts, whereas women who did not attend weekly reported 6.6 contacts $(t(458)=1.67 ; p=.09)$. They also reported seeing their contacts more frequently ( 7.5 versus $6.2 ; t(458)$ $2.61 ; p<.01)$. Neither emotional nor instrumental support was correlated with attendance frequency. Furthermore, none of these social network/support indicators were independently associated with AL in regression models; therefore, they could not be mediators on the pathway between religious service attendance and $\mathrm{AL}$.

\section{Additional Analyses}

We also conducted a secondary analysis among the 232 persons from New Haven for whom we had information about subjective religiosity and number of persons known in one's congregation to see whether these factors were associated with AL. First, the main association between weekly service attendance and AL among women was stronger in the New Haven group than in the entire sample $(\beta=-1.33$; $\mathrm{SE}=0.28 ; p<$ $.001)$. Subjective religiosity was not associated with AL. The number of persons known in the congregation was correlated with lower $\mathrm{AL}$ in the bivariate model, but did not remain significant after controlling for frequency of attendance $(b=$ -0.09 ; $\mathrm{SE}=0.21 ; p=.69$ ). AL levels did not differ significantly by denomination and adjusting for denomination did not alter the association between frequency of attendance and AL. Overall, we found that the effect of service attendance was independent of subjective religiosity or the number of persons known in one's congregation.

\section{DISCUSSION}

In this study, we found that weekly religious service attendance, defined as attending services at least once a week, was associated with lower levels of AL among high-functioning elderly women. This finding is consistent with the hypothesis that religious activity is associated with less system-wide "wear and tear" on the body among women who are otherwise 
TABLE 3. Linear Regressions Showing the Association Between at Least Weekly Service Attendance and Allostatic Load in Men and Women

\begin{tabular}{|c|c|c|c|c|c|c|}
\hline & \multicolumn{6}{|c|}{ Men } \\
\hline & \multicolumn{3}{|c|}{ Model 1} & \multicolumn{3}{|c|}{ Model 2} \\
\hline & $b(\mathrm{SE})$ & $t$ & $p$ & $b(\mathrm{SE})$ & $t$ & $p$ \\
\hline Weekly attendance (yes versus no) & $0.02(0.16)$ & 0.10 & .88 & $0.03(0.16)$ & 0.18 & .86 \\
\hline Age (years) & $0.03(0.03)$ & 1.11 & .27 & $0.03(0.03)$ & 1.05 & .29 \\
\hline Income (per $\$ 5000$ category) & $-0.07(0.03)$ & -2.02 & .04 & $-0.06(0.03)$ & -1.68 & .09 \\
\hline Education (years) & $0.00(0.03)$ & -0.03 & .98 & $0.00(0.03)$ & 0.02 & .98 \\
\hline White race (yes versus no) & $0.93(0.22)$ & 4.21 & $<.001$ & $0.90(0.22)$ & 4.09 & $<.001$ \\
\hline Married (yes versus no) & $-0.11(0.18)$ & -0.60 & .55 & $-0.14(0.18)$ & -0.80 & .43 \\
\hline Physical functioning (0.6-3.8) & $-0.15(0.20)$ & -0.76 & .45 & $-0.12(0.20)$ & -0.58 & .56 \\
\hline CHD diagnosis & & & & $0.08(0.24)$ & 0.31 & .76 \\
\hline Diabetes diagnosis & & & & $0.56(0.29)$ & 1.93 & .05 \\
\hline Cancer diagnosis & & & & $-0.33(0.26)$ & -1.26 & .21 \\
\hline $\mathrm{R}^{2}$ & .065 & & & .079 & & \\
\hline Adjusted $\mathrm{R}^{2}$ & .047 & & & .053 & & \\
\hline
\end{tabular}

$\mathrm{SE}=$ standard error

TABLE 4. Logistic Regression Results Showing the Association Between at Least Weekly Religious Service Attendance and Reporting a High-Risk Value on an Allostatic Load (AL) Component

\begin{tabular}{lcc}
\hline \multicolumn{1}{c}{ AL Component $^{a}$} & $\begin{array}{c}\text { Men } \\
\text { OR }(95 \% \mathrm{Cl})\end{array}$ & $\begin{array}{c}\text { Women } \\
\text { OR }(95 \% \mathrm{Cl})\end{array}$ \\
\hline High systolic BP & $1.80(1.12-2.90)$ & $0.77(0.49-1.23)$ \\
High diastolic BP & $1.31(0.83-2.08)$ & $0.87(0.53-1.41)$ \\
High waist/hip ratio & $0.61(0.39-0.93)$ & $0.34(0.18-0.67)$ \\
High cholesterol/HDL & $0.81(0.50-1.29)$ & $0.76(0.48-1.21)$ \\
$\quad$ ratio & & \\
High glycosylated & $0.94(0.58-1.52)$ & $0.79(0.49-1.27)$ \\
$\quad$ hemoglobin & $1.02(0.63-1.68)$ & $0.80(0.52-1.21)$ \\
High cortisol & $1.12(0.68-1.87)$ & $0.83(0.55-1.27)$ \\
High norepinephrine & $1.16(0.67-2.02)$ & $0.55(0.36-0.83)$ \\
High epinephrine & $0.90(0.58-1.40)$ & $1.09(0.64-1.87)$ \\
Low HDL cholesterol & $1.06(0.61-1.84)$ & $1.05(0.68-1.62)$ \\
Low DHEA-S & &
\end{tabular}

$\mathrm{OR}=$ odds radio $\mathrm{CI}=$ confidence interval $; \mathrm{BP}=$ blood pressure $; \mathrm{HDL}=$ high-density lipoprotein; DHEA-S = dihydroepiandrosterone sulfate.

${ }^{a}$ Models control for age, income, education, race, marital status, and physical functioning; each AL component is in a separate logistic regression model.

fairly healthy. Although several other studies have found associations between religiosity/spirituality and physiological markers such as IL-6, cortisol, or blood pressure, none have looked at a cumulative index of multiple physiological systems (10). The association between religious activity and an extensive measure, such as $\mathrm{AL}$, is meaningful because it illustrates how religious activity may affect the body through multiple systems. The fact that no single physiological marker drove the association between religious service attendance and $\mathrm{AL}$ in our study suggests that focusing on one or two biomarkers may fail to capture overall systemic relationships. AL captures dysregulation before the clinical onset of disease and so may detect physiological effects of religiosity sooner than studies using clinical outcomes. Detecting predictors of dysregulation early can be especially informative in research using elderly samples with a large loss to follow-up due to higher mortality rates. This may help to explain why many studies have found relationships between religious engagement and a wide range of diseases that have different pathological processes. Finally, our findings point to the prominence of religious service attendance per se in the association with AL that does not seem to hold for other domains of religiosity, such as subjective religiosity, number of persons known in the congregation, or denomination (the only other religious domains we had data on).

Why religious service attendance may influence cumulative physiological wear and tear remains to be determined. In this study, we considered whether increased social networks and supports might help to explain the significant inverse relation between religious service attendance and AL, but did not find support for this idea. Although individuals who attended services more frequently did have increased social networks and support, these social resources were not independently associated with AL. The failure of social networks and support to account for the relationship between religious service attendance and AL may be interpreted in several ways. It is possible that it is a more specific type of religiously based networks and supports that matters rather than differences in the general social networks of those who are and are not religiously engaged. However, we used a general measure of networks and support that did not distinguish between religious and nonreligious sources of support, and the type of social support that persons receive because they belong to a religious community may not have been well captured by such general questions. Thus, the debate over the role of social integration in the association between religiosity and health remains to be resolved (46).

Alternatively, other pathways may be involved. For example, certain beliefs and rituals linked to religious activity, but not dependent on the social component, may confer important psychological resources that buffer a stress response. Seeman and McEwen, for example, suggested that an experience of deep inner peace that may result from an activity, such as meditation or prayer, may lead to a shift from sympathetic 
TABLE 3. Continued

\begin{tabular}{|c|c|c|c|c|c|}
\hline \multicolumn{6}{|c|}{ Women } \\
\hline \multicolumn{3}{|c|}{ Model 1} & \multicolumn{3}{|c|}{ Model 2} \\
\hline$b(\mathrm{SE})$ & $t$ & $p$ & $b(\mathrm{SE})$ & $t$ & $p$ \\
\hline$-0.47(0.15)$ & -3.15 & .002 & $-0.47(0.15)$ & -3.13 & .002 \\
\hline $0.04(0.03)$ & 1.46 & .15 & & & \\
\hline$-0.05(0.03)$ & -1.47 & .14 & $-0.05(0.04$ & -1.47 & .14 \\
\hline $0.01(0.03)$ & 0.21 & .84 & $0.01(0.03)$ & 0.29 & .77 \\
\hline $0.28(0.18)$ & 1.53 & .13 & $0.33(0.19)$ & 1.74 & .08 \\
\hline $0.20(0.17)$ & 1.21 & .23 & $0.18(0.17)$ & 1.07 & .28 \\
\hline \multirow[t]{6}{*}{$-0.40(0.15)$} & -2.71 & .01 & $-0.38(0.15)$ & -2.58 & .01 \\
\hline & & & $0.16(0.35)$ & 0.47 & .64 \\
\hline & & & $0.44(0.27)$ & 1.67 & .10 \\
\hline & & & $0.02(0.19)$ & 0.11 & .91 \\
\hline & .059 & & .066 & & \\
\hline & .043 & & .043 & & \\
\hline
\end{tabular}

arousal to parasympathetic relaxation (47). Beliefs about the meaning of suffering, for example, may provide a way of coping with negative life events and thus mitigate the stress response associated with difficult life circumstances. More research is needed to further explore the interrelationships between different domains of religious activity, stress, and negative emotions to better understand how religious engagement may influence biological processes.

Our findings that the association between religious service attendance and $\mathrm{AL}$ is apparent only among women, but not men, is consistent with several other studies noting gender differences in the association between religious engagement and health $(4,48,49)$. There are several possible reasons for this observed difference. First, although women live longer than men, they experience higher levels of morbidity as well as more negative life events (50), potentially making the support offered by religious groups more integral to elderly women's health. In our sample, a larger proportion of women were widowed, whereas more men were currently married. It is possible that married men may not "need" the support associated with religious engagement because they receive the needed support from their wives. More broadly, if religious engagement is especially salient for those who are more vulnerable, then we might expect differential relationships between attendance and $\mathrm{AL}$ depending on an individual's level of vulnerability. Several researchers have found that the association between religious activity and health is stronger among women or among African Americans $(4,11)$. The role of social disadvantage in the relationship between religiosity and health is thus a promising area for future research.

Second, the composition of men and women in this sample may contribute to the observed gender differences. Given the gender differences in life expectancy, the men who were eligible to participate in the study were likely especially resilient, potentially more so than the women. Men were also more likely to be currently married. It is therefore possible that the men and women in this sample are not comparable in some important way having to do with resilience.
Third, it is also possible that the underlying experience that is captured by the one question on frequency of religious activity differs for men and women $(51,52)$. One group may go to services and return home, whereas the other becomes more involved in their religious community. Although both groups report weekly attendance, one is qualitatively more involved. More detailed questions regarding a person's religious experience within and outside of their faith community may help elucidate these differences.

Finally, the observed gender differences may reflect true underlying variation in physiological dysregulation in women and men. We observed gender differences both in the pattern of dysregulation itself as well as in the association between religious service attendance and magnitude of dysregulation. A growing number of studies have suggested that physiologically, men and women may respond differently to the social environment $(18,53)$. For example, Seeman et al. found that the relationship between several social integration/social support measures and AL differed by gender, with the main association stronger among elderly men than among women (18). Another study found that social integration was associated with C-reactive protein in men but not women (54). In our study, among men, there were few significant associations of religious attendance with the AL components, and findings with the overall AL measure were null (although the inverse finding for weekly religious attendance with higher systolic blood pressure among men is surprising). Future research is needed to better understand the observed gender variations in physiological dysregulation and how these relate to different types of exposures.

\section{Limitations}

The present study has several limitations. First, the possibility of reverse causality cannot be ruled out. However, the entire sample was high functioning, and hence, the variation in health and disability status was fairly limited, making our conclusions less likely to be confounded by differential changes in service attendance due to physical ability. Further- 
more, differential selection cannot explain the observed gender differences. Alternatively, a third unmeasured factor could be causing both a lower AL score and higher attendance. Potential factors like this could include family or community norms around social behaviors or even personality characteristics.

Another weakness of the study is that only one dimension of religious engagement was used in most of the analysisreligious service attendance. A more thorough description of religious activities and experiences could possibly shed more light on the pathways through which religious activity may affect physiological dysregulation, or why religious activity seems more salubrious for women than for men. Although not uncommon in social science research, the adjusted model $\mathrm{R}^{2}$ is small, suggesting that much of the variance in $\mathrm{AL}$ is not explained. The high-functioning persons in our study also had higher levels of education as compared with their lowerfunctioning counterparts. Our findings may therefore not be generalizable to persons with lower levels of functioning or lower socioeconomic status. Given the relatively high health status of our sample, we also observed a floor effect with the AL score with almost a quarter of participants having a score of 0 or 1 . Without capturing a wider range of physiological dysregulation, we are likely to be underestimating the association between religious service attendance and $\mathrm{AL}$, or missing possible threshold effects.

Finally, the AL measure itself is a simplified approach to understand the dynamic and synergistic physiological processes. Ideally, we would want to explore in more detail how religious activity is related to changes in various parameters from multiple physiological systems in response to specific stressors.

\section{CONCLUSION}

To our knowledge, this is the first study to examine the connection between any form of religious engagement and cumulative, systemic, indicators of physiological wear and tear. We found that weekly religious service attendance is associated with lower AL among high-functioning elderly women. It also seems that no one single physiological system is driving the observed association, suggesting that religious activity may have broad implications for multiple and diverse physiological processes.

\section{REFERENCES}

1. Powell L, Shahabi L, Thoresen C. Religion and spirituality, linkages to physical health. Am Psychol 2003;58:36-52.

2. Hackney C, Sanders G. Religiosity and mental health: a meta-analysis of recent studies. Journal for the Scientific Study of Religion 2003;42: $43-55$.

3. Comstock G, Partridge K. Church attendance and health. Journal of Chronic Disease 1972:665-72.

4. Strawbridge WJ, Cohen RD, Shema SJ, Kaplan GA. Frequent attendance at religious services and mortality over 28 years. Am J Public Health 1997;87:957-61.

5. Colantonio A, Kasl SV, Ostfeld AM. Depressive symptoms and other psychosocial factors as predictors of stroke in the elderly. Am J Epidemiol 1992;136:884-94.

6. Ai A, Dunkle R, Peterson C, Bolling S. The role of private prayer in psychological recovery among midlife and aged patients following cardiac surgery. Gerontologist 1998;38:591-601.

7. Kalb C. Can religion improve health? While the debate rages in journals and medical schools, more patients ask for doctors' prayers. Newsweek 2003;10:44.

8. Hill D, Pargament KL. Advances in the conceptualization and measurement of religion and spirituality. Am Psychol 2003;58:64-74.

9. Musick M, House JS, Williams DR. Attendance at religious services and mortality in a national sample. J Health Soc Behav 2004;45:198-213.

10. Seeman T, Dubin L, Seeman M. Religiosity/spirituality and health: a critical review of the evidence for biological pathways. Am Psychol 2003;58:53-63.

11. Koenig HG, George LK, Hays JC, Larson DB, Cohen HJ, Blazer DG. The relationship between religious activities and blood pressure in older adults. Int J Psychiatry Med 1998:28:189-213.

12. Koenig HG, Cohen HJ, George LK, Hays JC, Larson DB, Blazer DG. Attendance at religious service, interleukin-6, and other biological parameters of immune function in older adults. Int $\mathrm{J}$ Psychiatry Med 1997:233-50.

13. Lutgendorf SK, Russell D, Ullrich P, Harris TB, Wallace R. Religious participation, interleukin-6, and mortality in older adults. Health Psychol 2004;23:465-75.

14. Masters K, Lensegrav-Benson T, Kircher J, Hill D. Effects of religious orientation and gender on cardiovascular reactivity among older adults. Research on Aging 2005;27:221-40.

15. McEwen B, Stellar E. Stress and the individual: mechanism leading to disease. Arch Intern Med 1993:2093-101.

16. McCewen BS. Interacting mediators of allostasis and allostatic load: Towards an understanding of resilience in aging. Metabolism 2003;52 (10 Suppl 2):10-6.

17. Crimmins E, Johnston M, Hayward M, Seeman T. Age differences in allostatic load: an index of physiological dysregulation. Exp Gerontol 2003;38:731-4.

18. Seeman T, Singer B, Ryff CD, Love GD, Levy-Storms L. Social relationships, gender, and allostatic load across two age cohorts. Psychosom Med 2002;64:395-406.

19. Seeman T, Singer B, Rowe J, Horwitz R, McEwen B. Price of adaptationallostatic load and its health consequences. Arch Intern Med 1997: 2259-68.

20. Karlamangla A, Singer B, McEwen B, Rowe J, Seeman T. Allostatic load as a predictor of functional decline MacArthur studies of successful aging. J Clin Epidemiol 2002;55:696-710.

21. Seeman T, McEwen B, Rowe J, Singer B. Allostatic load as a marker of cumulative biological risk: MacArthur studies of successful aging. Proc Natl Acad Sci U S A 2001;98:4770-5.

22. Kubzansky L, Kawachi I, Sparrow D. Socioeconomic status, hostility, and risk factor clustering in the normative aging study: any help from the concept of allostatic load? Ann Behav Med 1999;21:330-8.

23. Seeman T, Singer BH, Ryff CD, Love GD, Levy-Storms L. Social relationships, gender, and allostatic load across two age cohorts. Psychosom Med 2002:395-406.

24. Seeman T, Glei D, Goldman N, Weinstein M, Singer B, Lin Y. Social relationships and allostatic load in Taiwanese elderly and near elderly. Soc Sci Med 2004;59:2245-57.

25. Chatters LM. Religion and health: public health research and practice. Annu Rev Public Health 2000;21:335-67.

26. Fetzer Institute NIoAWG. Multidimensional Measurement of religiousness/ spirituality for use in health research: a report of the Fetzer Institute/National Institute of Aging Working Group. Kalamazoo, MI: Fetzer Institute; 1999.

27. Idler E. Organizational religiosity. In: Multidimensional measurement of religiousness/spirituality for use in health research: a report of the Fetzer Institute/National Institute on Aging Working Group. Kalamazoo, MI: Fetzer Institute; 1999.

28. Jarvis GK, Northcott HC. Religion and differences in morbidity and mortality. Soc Sci Med 1987;25:813-24.

29. Bassuk S, Glass T, Berkman LF. Social disengagement and incidence of cognitive decline in the community dwelling elderly. Ann Intern Med 1999:165-73.

30. Bradley D. Religious involvement and social resources: evidence from the dataset "American's changing lives." Journal for the Scientific Study of Religion 1995;34:259-67.

31. Berkman L, Seeman T, Albert M, Blazer DG, Kahn R, Mohs R, Finch C, Schneider E, Cotman C, McClearn G, Nesselroade J, Featherman D, Garmezy N, McKhann G, Brim G, Prager D, Rowe J. High, usual and 
impaired functioning in community-dwelling older men and women: findings from the McArthur Foundation Research Network on Successful Aging. J Clin Epidemiol 1993;46:1129-40.

32. Katz S, Downs T, Cash H. Progress in the development of an index of ADL. Gerontologist 1970:20-30.

33. Nagi S. An epidemiology of disability among adults in the United States. Milbank Q 1976:439-68.

34. Rosow I, Breslau N. A Guttman health scale for the aged. J Gerontol 1966:556-9.

35. Pfeiffer E. A short portable mental status questionnaire for the assessment of organic brain deficit in elderly patients. J Am Geriatr Soc 1975: $433-41$.

36. Seeman T, Crimmins EM, Huang M, Singer B, Bucur A, Guenewald T, Berkman L, Reuben D. Cumulative biological risk and socio-economic differences in mortality: MacArthur studies of successful aging. Soc Sci Med 2004;58:1985-97.

37. Karlamangala A, Singer B, Seeman T. Reduction in Allostatic Load in older adults is associated with lower all-cause mortality risk: MacArthur studies of successful aging. Psychosom Med 2006;68:500-7.

38. Antonucci T. Social networks in adult life and a preliminary examination of the convoy model. J Gerontol 1987:42:519-27.

39. Seeman T, Berkman L. Characteristics of social networks in the provision of social support in the elderly: who provides support? Soc Sci Med 1988;26:737-49.

40. Blazer DG. Social support and mortality in an elderly community population. Am J Epidemiol 1982:684-94.

41. Seeman T, Syme SL. Social networks and coronary artery disease: a comparative analysis of network structural and support characteristics. Psychosom Med 1987;49:341-54.

42. Seeman T, Berkman L, Blazer D, Rowe J. Social ties and support and neuroendocrine function: the MacArthur studies of successful aging. Ann Behav Med 1994;16:95-106.

43. Seeman T, Charpentier P, Berkman L, Tinetti M, Guralnik J, Albert M,
Blazer DG, Rowe J. Predicting changes in physical performance in a high functioning elderly cohort: MacArthur studies of successful aging. J Gerontol 1994:M97-M108.

44. House JS, Robbins C, Metzner HL. The association of social relationships and activities with mortality: prospective evidence from the Tecumseh community health study. Am J Epidemiol 1982;116:129-40.

45. McFadden S. Religion, personality, and aging: a lifespan perspective. J Pers 1999;67:1081-104.

46. Joiner T, Perez M, Walker R. Playing devil's advocate: why not conclude that the relation of religiosity to mental health reduces to mundane mediators? Psychological Inquiry 2002;13:214-6.

47. Seeman T, McEwen B. Impact of social environment characteristics on neuroendocrine regulation. Psychosom Med 1996;58:459-71.

48. McCullough ME, Hoyt WT, Larson DB, Koenig HG, Thoresen C. Religious involvement and mortality: a meta-analytic review. Health Psychol 2000;19:211-22.

49. McCullough ME, Laurenceau J. Religiousness and the trajectory of self-rated health across adulthood. Personality and Social Psychology Bulletin 2005;31:560-73.

50. Davis M, Matthews K, Twamley E. Is life more difficult on Mars or Venus? A meta-analytic review of sex differences in major and minor life events. Ann Behav Med 1999;21:83-97.

51. Thompson E. Beneath the status characteristic: gender variations in religiousness. Journal for the Scientific Study of Religion 1991;30: 381-94.

52. Bednarowski MF. The religious imagination of American women. Bloomington and Indianapolis: Indiana University Press; 1999.

53. Kajantie E, Phillips DIW. The effects of sex and hormonal status on the physiological response to acute psychosocial stress. Psychoneuroendocrinology 2006;31:151-78.

54. Loucks E, Berkman L, Gruenewald T, Seeman T. Social integration is associated with fibrinogen concentration in elderly men. Psychosom Med 2005;67:353-8. 